\title{
APROXIMACIÓN AL ESTUDIO DEL DISCURSO EN LOS MANUALES DE HISTORIA: TRATAMIENTO DE LA FIGURA DEL HÉROE Y DEL COLECTIVO
}

\author{
María Elena Del Valle Mejías: Universidad Pedagógica Experimental Libertador, Caracas
} (Venezuela)

\section{Resumen}

El presente artículo es el resultado de un conjunto de reflexiones en torno a las características discursivas verbales y no verbales de los textos de Historia de Venezuela y su tratamiento del hecho histórico. Se compilan un conjunto de preocupaciones en relación al tratamiento de la figura del héroe y su excesiva valoración y la presentación del colectivo como mero observador de los acontecimientos históricos.

“Papá, explícame, ¿para qué sirve la historia?”, increpaba el hijo de Marc Bloch a su padre, y si algo hizo Marc Bloch a través de su obra fue contestarle, de manera contundente, con el ejemplo. Sus obras conjuntamente con las de Lucien Febvre le dieron a la ciencia histórica una nueva visión de los hechos, nos enseñaron a ir más allá de las fuentes, a derribar los cercados que separan a la historia de las otras ciencias enseñándonos a trabajar multidisciplinariamente, haciendo del hecho histórico una realidad en dialéctico movimiento, $Y$ es que esta incógnita (la utilidad de la historia) resuena en los oídos de los historiadores y estudiosos y desde hace algunos años en mi mente también, Qué sentido tiene conocer el pasado?, para que sirve llenarnos de datos y nombres que parecieran no tener nada que ver con lo que vivimos hoy?, qué sentido tiene una ciencia, que lejos de habilitarnos para cambiar nuestra realidad, nos postra dependientes en la espera de un héroe, que haga lo que espero o que enfrente lo que no soy capaz de enfrentar?

Esas son preguntas que quienes enseñamos historia debemos hacernos diariamente, y como didactas también debemos preguntarnos si nuestros textos y la manera como son escritos apuntalan estas apreciaciones, que le roban a la historia su papel liberador y dignificante de los pueblos. ¿Con nuestro discurso académico, le damos a la historia su verdadero papel o la volvemos un estudio estéril de hechos desconectados y sin impacto en la vida de los jóvenes?, es ese manual escrito respondiendo a una ideología, un instrumento silencioso que modela las mentalidades e inocula de manera imperceptible una visión del hecho histórico?, es ese discurso y su aproximación a la figura del héroe, una de las razones que afianzan el carácter dependiente de la mentalidad venezolana?, es la narración euro céntrica de los hechos una excusa perfecta para la subestimación de nuestros pueblos y su carácter protagónico? se le hace justicia al "Pueblo de Venezuela", ese abstracto que se cita en momentos oportunos, en la descripción de su participación en el logro de diversas empresas en la historia? Es su acción tan prescindible que no merece ser destacada en ese discurso? , busca ese texto la interacción productiva entre el lector y quien escribe? $O$ es tan solo la demostración de un saber acumulado que se presenta como un credo que debe ser aprendido como dogma de fe? Que efecto tiene ese discurso en quien lo lee? Motiva a ese joven no solo a la admiración casi mítica de sus héroes, sino 
también al auto-descubrimiento de las mismas potencialidades que llevaron a tantos a hacerse un nombre en los anales de la historia?

El discurso en los manuales de historia tiene unas características básicas que se evidencian en sus efectos:

En primer lugar, un culto al héroe desmedido, irracional y exagerado.

Escribe Montero:

"La tendencia a situar en los demás los propios problemas y sus soluciones puede conducir al extremo opuesto cuando sale a la superficie como el culto al héroe; o sea una exagerada admiración por otra persona (...) el culto al héroe es una forma de auto repudio. Hace que los otros sean más importantes que tu y condiciona tu propia realización a algo exterior a ti (...) se tú mismo, tu propio héroe" (2000: 78)

Este es sin duda, uno de los aspectos más importantes al analizar el discurso usado en los manuales de historia. Este héroe, su descripción, los atributos que acompañan la narración de sus proezas, los epítetos que se acuñan al nombre de cada héroe, el énfasis descriptivo de sus virtudes y el soslayo cómplice que se hace de sus defectos, el efecto en el imaginario colectivo que estas figuras ejercen, el cómo se han imbricado en nuestra realidad hasta el punto de no concebir los hechos históricos sin su presencia, son sin duda efectos de esta narrativa en el colectivo.

El uso de los pronombres personales, los adjetivos posesivos al momento de narrar un determinado hecho, elementos que se fusionan en la semántica y en la pragmática del lenguaje llegando a configurar construcciones mentales instaladas muchas veces sin remedio en la psiquis del alumno, la conjugación de los verbos en la tercera persona del singular, atribuyéndole a un solo hombre los logros de un colectivo que también participa en la historia y que en la mayoría de los casos es el fiel de la balanza que determina la derrota o la victoria, todos estos elementos que se presentan de manera natural como parte de un género expositivo, tienen un efecto, forman una idea de lo que el hecho histórico significa.

Afirma Wenceslao Vargas Márquez (2003), historiador mexicano:

“¿Qué hace el héroe? ¿Existe el héroe? O existe el hombre común que toma una decisión cívicamente justa y decide arrostrar las consecuencias?" Entiéndase bien, no se trata, de no rendir el honor a quienes lo merecen porque son y han sido, esos que decidieron arriesgarse a dar el primer paso, o a alzar por primera vez la voz, sino de presentarlos en su justa medida, como hombres y mujeres que pueden ser emulados por cualquiera que decida actuar de manera cívica también, se trata, de dignificar a quien lee la historia en esos textos, haciéndolo sentir partícipe y protagonista de lo que ocurra en su país de ahora en adelante, y sobre todo dueño de su destino. Los héroes forman parte de la construcción de la identidad nacional y por lo tanto son una necesidad, forman parte de esos elementos que obsequian a los pueblos razones para el orgullo y la autoestima, son el pasado de los pueblos y por lo tanto, constituyen ese anecdotario que repiten los cronistas y que los literatos detallan con prolijos adjetivos. 
Lo que no deben provocar, es la parálisis de las iniciativas particulares. La historia no debería consistir, como afirmó Thomas Carlyle: "en la biografía de grandes personalidades", sino en la acción conjunta y convencida de quienes se saben copartícipes también de esa cotidianidad en apariencia insignificante, que es la realidad que subyace en lo que registran los textos. Sin duda alguna, se trata de un discurso que persigue un propósito, que responde a una ideología y que tiene una agenda clara. Todos los que hemos sido formados de la mano del Dr. Manuel Carrero o del Dr. Diógenes Molina, sabemos que hay historias que no se han escrito todavía y que también hay historias que han sido escritas para redimir al vencedor. Puede eso estar pasando en el discurso de los textos históricos? Responde, el discurso histórico a las competencias intelectuales de los jóvenes que los reciben?

Según la Taxonomía de Bloom (1989), los alumnos de esta etapa, en edades comprendidas entre 13 y 15 años, están ya en condiciones de lograr el nivel más alto de la misma, y los verbos usados en la redacción de objetivos son los más complejos, analizar, establecer juicios de valor, es ese el objetivo del discurso planteado?, Cuál es la función de esos textos: informar, describir, narrar?, no deberían, al menos intentar comprometer al joven con su proceso de aprendizaje, con el hecho histórico mismo?, o la función de su discurso es sólo negar, afirmar y argumentar de manera directiva sin proponer la construcción de los conceptos involucrando al alumno como parte activa del proceso?, es el discurso académico una estrategia de captación a una determinada idea, establece, el autor esquemas de pensamiento definitivos con respecto a hechos del pasado y además no propone ningún tipo de actitud reflexiva por parte del estudiante? Los niveles de veracidad con los que se presentan los hechos, responden realmente a una aproximación objetiva al suceso?

Las veces que los autores apelan al conocimiento compartido, lo hacen en función de afirmaciones que ellos mismos presentan o en realidad ese saber ha sido construido por ambas partes, como intentan hacer creer? Es el conocimiento, un proceso dialéctico, en el que se revisan regularmente, fuentes y nuevas teorías, para agiornarlo a los tiempos o tienen como objetivo formar una matriz de pensamiento?." Los actos de habla, como las órdenes, los imperativos, los atributos, presuponen siempre diferencias de poder y autoridad", afirma Van Dijk (1992), el discurso de los textos, es el discurso del poder, es el discurso de una elite, que intenta, aprovechando muchas veces lo maleable de la condición neófita del lector, formar una idea que, rara vez es refutada y que contribuye al afianzamiento del "statu quo" en la perspectiva que tiene el joven de su historia.

El héroe y sus características, los hechos a los que son asociados, lo dependiente de su accionar que se presentan los hechos registrados en la historia, son como ya se ha expuesto, elementos que le dan al discurso histórico de los manuales un perfil y un efecto pocas veces benévolo con el proceso de aprendizaje eficaz que persigue la educación y en segundo lugar: la figura del colectivo.

Hay un ejemplo, que expresa de manera gráfica y contundente como el colectivo es presentado, a través del discurso histórico de los manuales: cito de la obra: Historia de Venezuela $7^{\circ}$ grado, de Guillermo Morón: "Es la mañana del 19 de Abril de 1810, el pueblo está en la plaza reunido y Emparam le pregunta, si quiere que él continúe en el mando, a lo que el pueblo responde inicialmente que si, el Padre Madariaga, ubicado detrás de Emparam, hizo señas a la multitud ,que siguiendo sus indicaciones rechazó a Emparam, en virtud de lo cual, éste renunció" pág. 146. Analicemos de manera, superficial, en virtud del 
tiempo, la aproximación al concepto de colectivo expresado en este fragmento: - cuál es el papel jugado, por el colectivo, sustantivado en "el pueblo"?, su presencia se describe como definitiva para la renuncia de Emparam, dice el autor: "en virtud de su rechazo, renunció", sin embargo su decisión se presenta como caprichosa, sin base y convicción, cuando en el mismo párrafo, el pueblo afirma querer que Emparam lo gobierne y 2 líneas después, por los gestos del Padre Madariaga, cambia de opinión.

Qué implicaciones tiene en la pragmática del discurso, un colectivo adjetivado de esta forma? Quién es el colectivo?, es acaso el alumno que lee, parte de ese colectivo? Y si ese es el caso, ¿no es preocupante que ese pueblo no sepa a ciencia cierta, que desea para su futuro?, no se le da acaso, extremada beligerancia al Padre Madariaga, como figura de autoridad, al influir de manera tan determinante la decisión del "pueblo"? Son muchas preguntas, y cada una de ellas merece y requiere tiempo y consideración. Teniendo en cuenta las palabras de Adriana Bolívar, "todo texto nace para cumplir una necesidad específica en el contexto de una sociedad" (2001:123), por lo tanto los textos denominados didácticos, tienen una función que amerita ser revisada. En función, del papel a jugar por el texto y su discurso y sobre todo en función de los efectos que estos tienen en la formación de las mentalidades, de la semiótica social y del imaginario colectivo, es imperativo, detenerse e interrogarse sobre el rumbo por el que vamos encaminados. La Historia, como ciencia social, debe entonces revisar su papel en estos tiempos, que sin duda no son los mismos en los que muchos de estos manuales fueron escritos.

Como afirma Javier Meneses Linares (2004): "En el momento actual (...) se perfila la urgencia de repensar el oficio del historiador, introduciendo en la agenda su papel como intelectual generador y difusor del saber aprendido" ( $p$ 12), si es una realidad la crisis de valores y de identidad que aqueja a nuestro país, no podemos, como agentes socializadores, sentirnos ajenos ni asistir como convidados de piedra a la fragmentación progresiva y silenciosa de nuestro ser nacional.

La formación de un nuevo ciudadano, crítico, analítico y comprometido, debe ser nuestra premisa, como afirmó Mariano Picón Salas: (1984)“ el nuevo sujeto social es el que es capaz de integrar su educación, para conquistar con mayor belleza, pasión y libertad, lo que le niega el mundo" ( $p$ 195) Descubramos la silente heroicidad de lo cotidiano, y rescatemos para los pequeños actos cívicos su justo valor, quitemos la hojarasca que opaca los hechos que no registran los textos, hagamos que con nuestro discurso académico, el alumno descubra que él puede ser su propio héroe, cuando decide arriesgarse a ser y a hacer su propios derroteros, teniendo el coraje de dudar, de interrogarse, de hacer su parte por una realidad mejor.

Permítanme terminar con unas palabras de Thomas Carlyle que envuelven el objetivo de esta reflexión:"Qué haya un hombre que muera ignorante, teniendo la capacidad para conocer, esto es lo que yo llamo una tragedia", tragedia de la cual nos hacemos cómplices si no cumplimos el papel al que estamos llamados, nuestro país, tiene ya suficientes tragedias, evitémosle una más, dando las herramientas que como pedagogos poseemos a nuestros estudiantes, y empezaremos a construir las bases de ese nuevo sujeto que reclama nuestro tiempo. 


\section{Bibliografía}

BLOOM, Benjamín. (1989). Taxonomías. México. Paidos.

BOLÍVAR, Adriana. (2001). Discurso e interacción en el texto escrito. Caracas. U.C.V

BLOCH, Marc. (1986). Apología de la historia o el oficio de historiador. Caracas. Fondo Editorial Lola de Fuenmayor.

CARLYLE, Thomas. (1999). Los héroes y el culto al héroes. México. Paidos.

MENESES, Javier. (2004) .De la nueva historia y del nuevo papel del historiador. México. Paidos.

MONTERO, Maritza. (2000) .Psicología Social. Caracas. U.C.V.

MORÓN, Guillermo. (2002) Historia de Venezuela. Caracas. Editorial Salesiana.

Picón Salas, M. (1984) Ensayos Escogidos. Santiago de Chile, Editorial Zig- Zag. 195

VAN DIJK, Teun. (1992). De la gramática del texto al análisis del discurso. España. Gedisa.

VARGAS, Wenseslao. (1999). El culto al héroe. México. Paidos. 